Muiraquitã, PPGLI-UFAC, v.2, n.1, Ju1/Dez, 2013

\title{
OJOS CHILENOS Y MAPUCHES: LA FOTOGRAFÍA SOBRE EL MAPUCHE DE GUSTAVE MILET DE FINES DEL XIX
}

\author{
Marcela Orellana Muermann \\ Universidad de Santiago de Chile
}

\section{RESUMO}

No século XIX, o recém governo independente do Chile constrói para o exterior uma imagem que caracterizava estas terras por sua homogeneidade racial, a fim de incentivar a migração estrangeira e o investimento do capital estrangeiro. Além disso, simultâneo a esse discurso, construiu-se um registro fotográfico extenso que evidencia a presença Mapuche no território. No entanto, o registro apresenta um discurso sobre o mapuche em que, embora mostre aquela comunidade, oculta sua cultura. Analisamos aqui a produção fotográfica de um dos fotógrafos da época, Gustavo Milet e tentamos contrastá-la com a opinião e com o olhar mapuche, quando as poucas fontes sobre o assunto o permitiram. PALAVRAS-CHAVE: Mapuches. Fotografia. Chile. Gustave Milet. Século XIX.

El conquistador Pedro de Valdivia muere en 1553 a manos de los mapuches, y de acuerdo a la leyenda, se muere comiendo oro obligado por sus captores. Este acto evidencia, a la vez que un sentimiento de incomprensión de parte de los indígenas frente a la avidez de riquezas, un deseo de castigo y venganza frente a quien simbolizaba la invasión, la agresión y la imposición de una cultura extraña. Pero, ningún acto simbólico fue capaz de detener la historia y el año 1882 se llegó a un acuerdo de paz por el cual los mapuches reconocían al gobierno de Chile y se sometían a sus mandatos. El 1ero de enero de 1883 se funda la ciudad de Villarrica, hecho que marcó el fin de la vida mapuche independiente.

Mientras en Chile de fines del XIX, chilenos y mapuches se disputaban el territorio al sur del río Bío Bio tras una prolongada guerra de más de tres siglos, hacia el exterior se construía una imagen que caracterizaba a estas tierras por su homogeneidad racial en vistas a 
fomentar la emigración extranjera así como la inversión de capitales foráneos. Subyacía la concepción de que "una nación racialmente homogénea, cuya población sería europoide, carece de conflictos interétnicos y pertenece al mundo civilizado" (SAMANIEGO, 2007, p. 33). Una clara muestra es la exposición que hace Diego Barros Arana en su artículo "La homogeneidad étnica en Chile" de 1875 donde afirma: "La raza chilena ha desaparecido, i la lengua de los antiguos pobladores de Chile es absolutamente desconocida en el resto del territorio... Así pues, haciendo abstracción de los cuatro mil fueguinos que habitaban las islas del sur i de los cuarenta o cincuenta mil araucanos, que viven encerrados en una porción reducida del territorio i que cada día se hace más estrecho, todo Chile es poblado por una sola raza en que predomina el elemento europeo más o menos puro, i que no se habla más que un solo idioma, el español" (SAMANIEGO, 2007, 34).

Esa "porción reducida del territorio", es también el escenario de una producción fotográfica sobre sus habitantes. Los llamados fotógrafos de la Frontera, Enrique Valk, que llega al país en 1852, el canadiense Obder Heffer que llega en 1886 y Gustavo Milet, francés nacido en Valparaíso, hacen un amplio registro fotográfico que se convierte en una negación de ese discurso oficial que intenta borrar la cultura a fin de mostrar un país racialmente homogéneo. La fotografía afirma una existencia mapuche.

Sin embargo, mostrar una existencia no significa necesariamente reconocer la otredad de una cultura. ¿Cómo se muestra al sujeto mapuche? Para responder esa pregunta recorreremos en este artículo la producción fotográfica de Gustav Milet, que se instala a vivir en la Frontera en 1890 y abre un estudio fotográfico en la ciudad de Traiguén. Milet comercializa su producción en tarjetas postales a través de las cuales el mapuche puede ser visto por ojos muy lejanos a su territorio. 
Si disponemos de esta fuente fotográfica, existe también un registro, menos numeroso y más difícil de encontrar, de la voz mapuche. Intentaremos dar la voz al mapuche cuando sea posible, como un contrapunto a la imagen que construye de ellos el fotógrafo Milet.

\section{La fotografía, realidad y punto de vista}

La fotografía, inventada en 1839, nace bajo el signo de la realidad. André Bazin destaca la objetividad del proceso: "Con la fotografía se da una satisfacción completa de nuestro deseo de semejanza por una reproducción mecánica de la cual el hombre queda excluido" (BAZIN, 1990, p. 26) y la consecuencia para quien mira una imagen fotográfica: "Esto le da una credibilidad, nos vemos obligados a creer en el objeto representado, re-presentado efectivamente, es decir, hecho presente en el tiempo y en el espacio" (BAZIN, 1990, p. 28).

Barthes por su parte nos muestra el valor que adquiere una fotografía gracias a la reproducción de la realidad: "La fotografía es la autentificación misma" (BARTHES, 2002, p. 151) nos dice en la Cámara Lúcida. "El pasado es desde entonces tan seguro como el presente. Lo que se ve en el papel es tan seguro como lo que se toca" (BARTHES, 2002, p. 152).

La fotografía sobre el mapuche muestra entonces una realidad, sin embargo, al mismo tiempo, está mediada por la mirada de quien la realiza, de manera que además de una representación de la realidad hay un discurso sobre esta. Es el fotógrafo quien elige como mostrarnos lo que quiere que veamos: el ángulo, la pose, la iluminación, el encuadre, todos elementos que hacen que detrás de una fotografía exista un punto de vista. Así, el fotógrafo, al igual que el narrador, es un mediador entre la historia o lo que quieran mostrar y lo que en definitiva, narrar o muestran. 


\section{La fotografía de Milet sobre el mapuche}

Durante los años en que Milet es un activo fotógrafo, el género fotográfico por excelencia es el retrato. $Y$ de acuerdo a esta tradición la persona será presentada en una composición donde la pose está tan codificada como la escena total que se logra con un telón de fondo y elementos de decoración que permitan identificar al fotografiado, como serían por ejemplo libros para un intelectual o instrumentos de navegación para un navegante. El retrato de la mujer mapuche que realiza Milet es, sin embargo, lo contrario a la caracterización individual.

Milet retrata a mujeres mapuches en su estudio de Traiguén y trabaja la composición de sus fotografías. Las poses en las cuales prepara y dispone a sus sujetos corresponden a las propias del género del retrato occidental, miradas de frente o desde un ángulo de tres cuartos, a través de lo cual Milet lleva a los sujetos mapuches fotografiados a códigos conocidos, hacia lo propio, dejando de lado posturas espontáneas o características. El conjunto de retratos está agrupado en tarjetas postales bajo el nombre genérico de "Indios araucanos de Traiguén", ningún nombre que individualice a un sujeto como en el retrato canónico, más aún cuando muchas de ellas lucen las mismas joyas, presumiblemente por tanto del fotógrafo, y no de cada una. Se nos muestran personas anónimas.

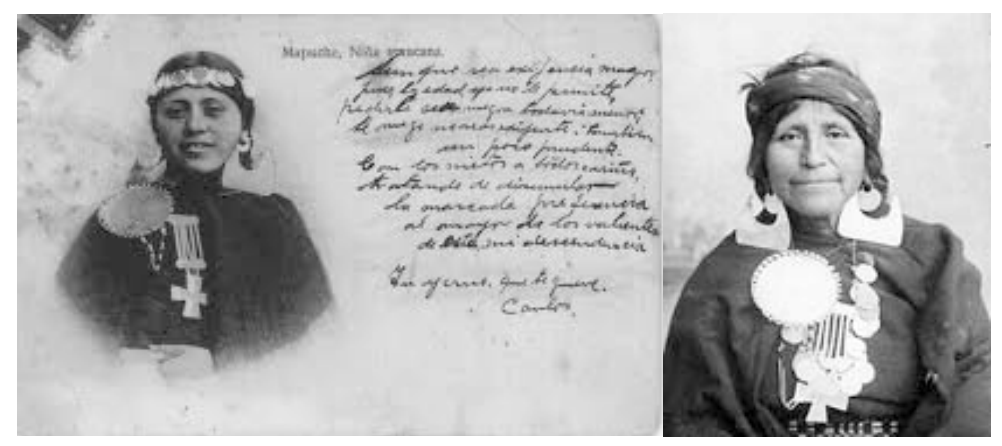


La foto de estudio tiene efectos sobre los sujetos fotografiados. Extrae a las personas de su contexto y los pone "fuera de los accidentes de la vida diaria" (PENN, 1974, p. 8), arrancándolos de su tiempo real, tal como afirma Irvin Penn a raíz de su experiencia de fotografiar indígenas de distintas partes del mundo en un estudio movil "Sacar a la gente de sus circunstancias naturales y ponerlos en el estudio al frente de una cámara no solamente los aísla, los transforma" (PENN, 1974, p. 9). Los retratos en estudio de mujeres mapuches que realiza Milet no solo las separa de su vida diaria si no que se ignora su otredad. Al atraerlas hacia sus códigos conocidos adoptando poses huincas, Milet las "civiliza". En eso es un hombre de su tiempo, la consolidación de la nación independiente aúna la imaginación del chileno en la cual no hay cabida para la diferencia indígena. Milet se instala en Traiguén solo siete años después de la pérdida de los territorios mapuches, fotografía al mapuche vencido, aquel que ya perdió sus tierras y se allana a los códigos que el artista le pida. Barthes recuerda en la Cámara Lúcida su experiencia como sujeto fotografiado: "Los otros me despropían de mí mismo, hacen de mi, ferozmente un objeto, me tienen a su merced, a su disposición” (BARTHES, 2002, p. 47).
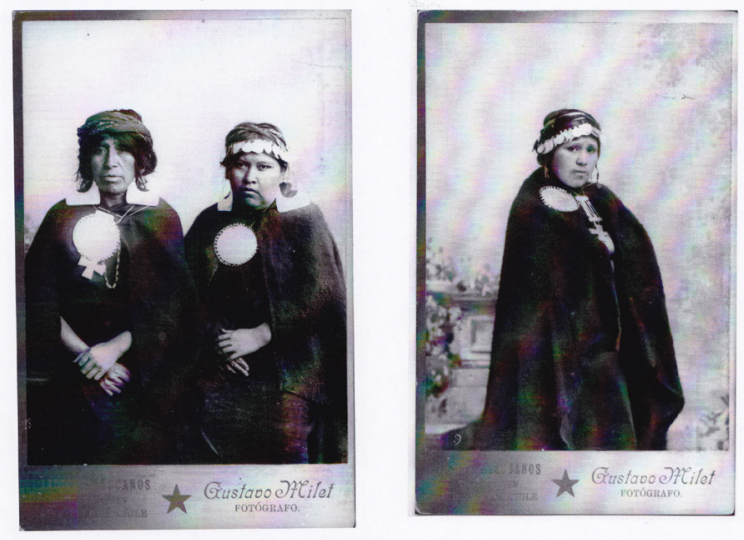
Desde el lado mapuche la "civilización" es vista desde ojos lúcidos, el sometimiento político no conlleva una pérdida de identidad. Lorenzo Kolipán expresa su opinión frente a la "civilización" en entrevista a Tomás Guevara "Después que se acabó nuestra independencia, se concluyó también ese beneficio; lo que hemos conseguido con la civilización que dicen que nos han dado es vivir apretados como trigo en un costal (GUEVARA, p. 27). Por su parte Juan Kalfucura y Juana Malén comentan un dicho a Guevara "quieren hacer pueblos, decía, para acorralarnos como vacas" (GUEVARA, p. 72).

Milet también inmoviliza en el estudio costumbres indígenas. Con ello logra un contrasentido con un resultado teatral, una costumbre fuera de contexto lleva al simulacro. Este tipo de fotos muestran un elemento exótico y "salvaje", prueba de la necesidad de guiarlos hacia la "civilización". Contribuye al efecto teatral el telón de fondo de corte romántico, que representa el interior o terrazas de casonas o palacetes. El piso en cambio está cubierto de paja en un clara contraste con el presumido mundo del telón. El contraste de entre la cultura del fotógrafo con la del fotografiado queda en flagrante evidencia.

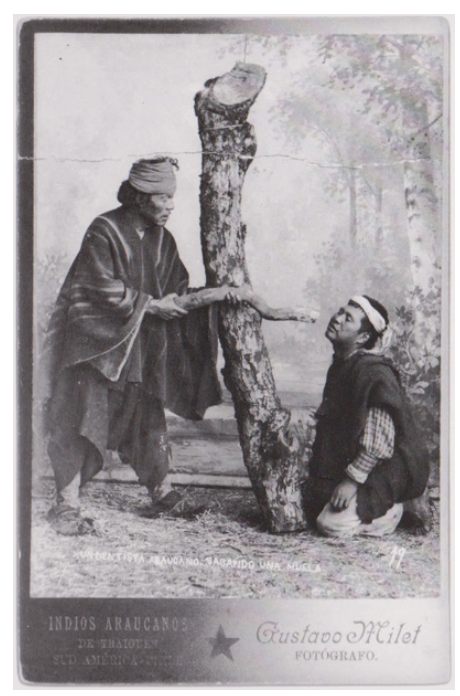


La fotografía de personas mapuches al aire libre, si bien menos numerosa que la de estudio, también parece dirigida por el fotógrafo que busca una composición ordenada de la imagen a fijar, el control de la escena. Siguiendo a Sontag en sus comentarios acerca de la fotografía turística, se trataría de la posesión de un espacio donde quien fotografía está inseguro (SONTAG, 2006, p. 23). Podríamos leer esa fotografía sobre los mapuches como un intento por tomar posesión de un espacio poco seguro. En suma, y si además ponemos al sujeto mapuche en poses huincas, la fotografía aparece también como un acto de conquista.

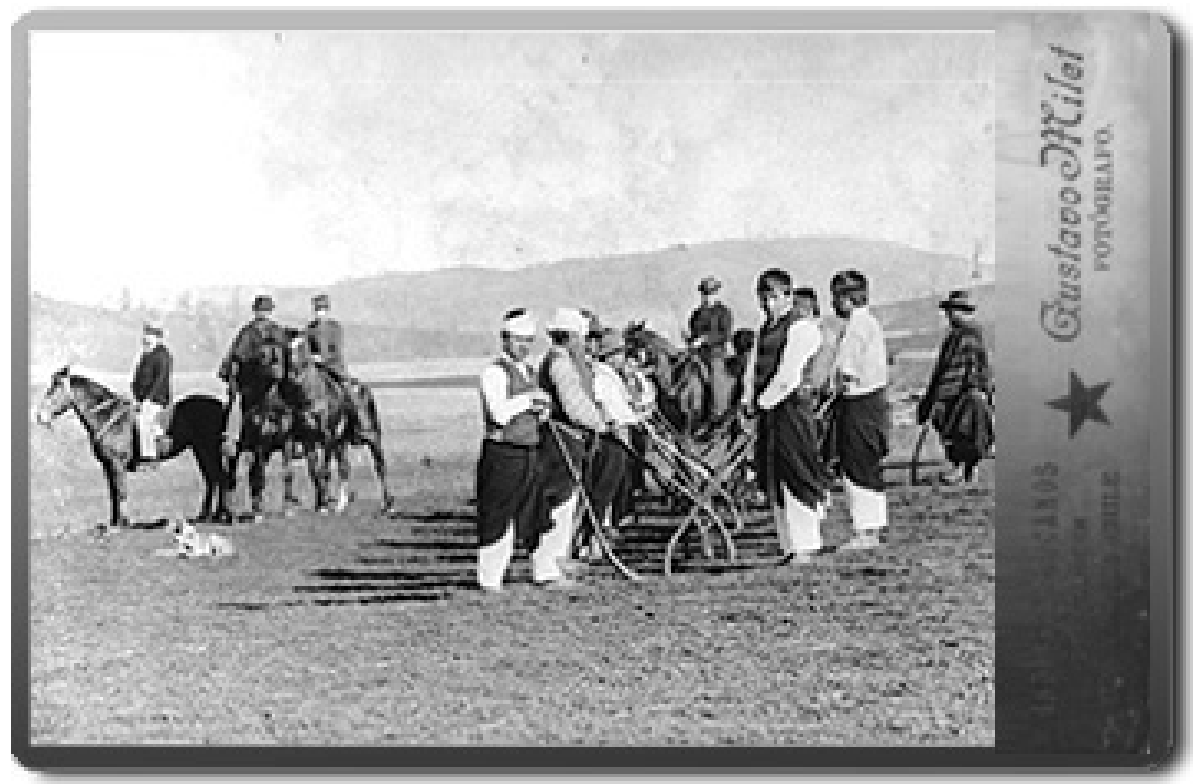

Las fotografías de Milet responden al intento de atraer al mapuche a la cultura chilena, a la idea de la necesidad de "civilizarlos". Su mirada oculta una otredad, y aspectos importantes de esta como es la relación del mapuche a su tierra quedan excluidas en las fotos de estudio, no vemos sus oficios ni sus habitaciones. Vemos personas al ser- 
vicio de un artista que los dispone en sus composiciones fotográficas sin ver su cultura. Ana Pizarro destaca el ocultamiento de la diferencia en el discurso de fines del XIX "la heterogeneidad, que era connatural a una nación periférica hereditaria de estructuras coloniales, se invisibiliza en el discurso constructor de los sectores hegemónicos y la fuerza coercitiva de su proyecto se impone" (PIZARRO, 2003).

Pero, si Milet mira desde sus ideas y construye un discurso en imágenes, ¿cómo miran los mapuches a la fotografía? En efecto, tiene razón Berger al afirmar "vemos con lo que sabemos y con lo que creemos" (BERGER, 2002, p. 13). A saberes y creencias distintas corresponden distintas miradas.

El cacique Pascual Coña que dicta su vida al sacerdote capuchino Ernesto Wilhelm de Moesbach da a conocer la reacción de sus padres alrededor de 1870 al recibir una fotografía suya que él les envía desde Santiago donde cursa estudios técnicos. Al mirarla, amigos de sus padres les previenen que "Tu hijo ha muerto, esa es el alma de un difunto" (COÑA, 1913, p. 89). Los padres mandan a buscar al hijo a Santiago para cerciorarse de que realmente este vivo y el joven Pascual Coña debe volver a la tierra de sus padres. La lectura de la fotografía del joven Coña no tiene como referencia la identidad de la foto al modelo, por el contrario, se nos afirma que lo que muestra la imagen no corresponde a lo que es. ¿dónde queda la autentificación, la imagen incuestionable de la realidad? Lo que nos parecía tan evidente, la autentificación de lo fotografiado no lo es para una cultura oral que no conoce ni la escritura ni la reproducción de imágenes.

Miran también desde otros saberes y creencias cuando en 1998 Juan Yevilao y su señora Aída Herrera reciben una foto que la antropóloga Magali Mella les había sacado el año anterior. ¿Quién es ese caballero que está al lado mío? pregunta la sra Aída mirando la imagen 
de su marido. Tampoco él se reconoce para comentar luego "que viejo estaba en esa foto" (MELLA, p. 51). Don Ignacio Ancalao Huenupil al verse en una fotografía tomada por la misma antropóloga reconoce en ella a su hermano muerto y dice "las fotografías son recuerdos que a uno le quedan cuando uno se muere... Es un recuerdo que a uno le queda y se alegra al verlo. Yo ayer me alegré cuando llegué con la foto y me acordé al tiro del finado de mi hermano. Al verla se parece, y le dije a mi señora "mire donde esta mi hermano". Y ella me dijo, "es tu hermano". Mella Luego aclara: le dije a mi señora "mira mi hermano no está muerto, mira donde está" (MELLA, p. 53).

De acuerdo a esta otra mirada de comunidades mapuches mayoritariamente orales, la fotografía no puede ser vista entonces como autentificación, como una muestra desde "lo real tangible". La fotografía sería un punto a partir del cual se puede ver más allá de lo representado. La fotografía aparece como una imagen fija a partir de la cual la mirada puede expandirse en diversas direcciones temporales, y de existencia, es una apertura a partir de lo representado, es en suma una experiencia visual diferente a la occidental, Puede hacer ver otras personas, otros tiempos, y si la fotografía detiene y fija el tiempo, la mirada mapuche lo expande a partir de ese momento detenido.

\section{A modo de conclusión}

Para terminar me pregunto si Pascual Coña o una de las tantas mujeres mapuches retratadas por Milet al ver sus fotografía dirían lo mismo que Theresa Harlan, fotógrafa nativa americana al recorrer, en 1998, una exposición sobre el oeste americano y ver las fotos sobre indígenas "sentí la ausencia de nuestra presencia indígena" (HARLAN, 2006, p. 228).

La fotografía sobre el mapuche es un registro indesmentible, en 
ese sentido niega un discurso oficial que busca ocultar la presencia de una comunidad mapuche, y por el contrario la exhibe. Sin embargo, a través del ejemplo de la fotografía de Milet, la fotografía en un instrumento más de negación de una cultura, un intento de civilización, un arma de dominación, un discurso que no otorga identidad, sino que la resta.

OLHOS CHILENOS E MAPUCHE: A FOTOGRAFIA SOBRE O MAPUCHE DE GUSTAVE MILET DO FINAL DO SÉCULO XIX

\section{RESUMEN}

En el siglo XIX, el reciente gobierno independiente de Chile construye hacia el exterior una imagen que caracterizaba a estas tierras por su homogeneidad racial en vistas a fomentar la emigración extranjera y la inversión de capitales foráneos. Por otra parte, simultáneamente a este discurso, se construye un amplio registro fotográfico que evidencia la presencia mapuche del territorio. El registro sin embargo presenta un discurso sobre el mapuche que, si bien muestran una comunidad, oculta su cultura. Revisamos aquí la producción fotográfica de uno de los fotógrafos de la época, Gustavo Milet e intentamos contrastar con la opinión y mirada mapuche, cuando las escasas fuentes sobre el tema lo permiten.

PALABRAS-CLAVE: Mapuche. Fotografía. Chile. Gustave Milet. Siglo XIX.

\section{REFERÊNCIAS}

BARTHES, R. La Cámara Lúcida. Nota sobre la Fotografía. Barcelona: editorial Paidós, 2002.

BAZIN, A. ¿Qué es el cine?, Ontología de la imagen fotográfica. Madrid: Ediciones Rialp, S.A., 1990.

BERGER, J. Modos de Ver. Barcelona: Editorial Gustavo Gili, S.A., 2002. COÑA, P. Testimonio de un cacique mapuche. Texto dictado al padre GUEVARA, T. Ultimas Familias y Costumbres Araucanas. (tomo VII de la serie). Santiago de Chile. Imprenta, Litografía i Encuadernación "Barcelona", 1913.

HARLAN, T. Fotografía, Antropología y Colonialismo (1845-2006). Ajuste de enfoque para una presencia indígena. Juan Naranjo editor. Bar- 
celona, Editorial Gustavo Gili, SL, 2006.

MILET, G. Serie Indios Araucanos de Traiguén. Sud América, Chile, en: Mapuche. Fotografías siglos XIX y XX. Construcción y Montaje de un Imaginario. Margarita Alvarado P, Pedro Mege R. Christián Báez A. Editores. Santiago: Editorial Pehuén, 2001.

MOESBACH, E. W. de. Biblioteca del Bicentenario, Libro XV, Santiago: editorial Pehuen, 2002.

PENN, I. Words in a small Room. New York, Viking Press, 1974.

PIZARRO, A. Ficciones y silencios fundacionales. Literaturas y culturas poscoloniales en América Latina (siglo XIX). Discursos de la sospecha. Referentes para evaluar la idea de nación. Friedhelm Schmidt-Welle editor. Vervuet: Iberoamericana, 2003.

SAMANIEGO, A. Mentalidades y politicas wingka: pueblo mapuche entre golpe a golpe (de Ibañez a Pinochet). Madrid, Consejo Superior de Investigaciones científicas, 2007.

SONTAG, S. Sobre la Fotografía. Buenos Aires: Alfaguara, 2006. 